\title{
THE BACTERIAL CELL
}

\author{
BY \\ ROBERT CRUICKSHANK \\ From the Bacteriology Department, University of Edinburgh
}

Our approach to the bacterial cell depends on our particular interests. The geneticist finds it a most useful plastic tool for studying mutations and variations, transductions and transformations; the chemist is interested in it as a source of enzymes of bewildering variety; he also helps in identifying the various components of the cell by fractionation and detailed chemical analysis of bacterial cell masses; the cytologist is mainly concerned with the anatomy of the cell, using modern staining and microscopic methods, including phase-contrast and electron microscopy; the bacteriologist is interested in the cell's interaction with its immediate environment, whether that be living tissue or dead and decaying matter.

For clinical pathologists gathered together to do honour to Virchow, it would seem most important to discuss, if only in outline, our modern concepts of the anatomy and physiology of the bacterial cell.

\section{Definition}

Bacteria belong to the kingdom of Protista, which also includes plant and animal forms and has many resemblances to the blue-green algae. According to majority opinion at the present time, the bacterium may be unicellular or multicellular, with haploid nuclear or chromatin material occurring as a single body and dividing by transverse fission. Cell division depends on constrictive ingrowth of the cell wall and cytoplasmic membrane.

Let us start with a simple diagrammatic representation (Fig. 1) of the bacterial cell. It is enclosed in a cell wall from which there may be extruded flagella and fimbriae and may be surrounded by a capsule. The main function of the cell wall is to give form and rigidity and some protection to the functional cell or protoplast. The cytoplasm has a lining or membrane which acts as a selectively permeable osmotic barrier and contains within it many granules varying in size from 10 to $20 \mathrm{~m} \mu$, composed mainly of ribonucleic acid (R.N.A.). Various inclusion bodies, such as volutin granules, lipid granules, etc., may be contained within the cytoplasm, and we shall refer to these later. The nuclear or chromatin material has the chemical and staining reactions of desoxyribonucleic acid (D.N.A.), but cannot be regarded as a nucleus in the sense that we use the term for animal cells, since there is no nuclear membrane, no centriole, and no unequivocal evidence of division by mitosis.

\section{Cell Wall}

Although a rigid lining membrane for the bacterial cell, similar to that for the fungus mycelium, was postulated by Cohn in 1875 , it is only since the introduction of electron microscopy that cell walls have been clearly demonstrable. From bacterial suspensions which have been mechanically or sonically disrupted, the cell walls can be separated from the electronically more opaque cytoplasm by high-speed centrifugation at 8,000 to 10,000 r.p.m., after first removing any intact cells at 2,000 to 3,000 r.p.m. It is less easy to get pure cell walls with Gram-negative than with Grampositive cells, and mechanical disruption gives better results than sonic disintegration. The cell wall constitutes about $20 \%$ of the dry weight of Gram-positive cocci and as much as $45 \%$ for $C$. diphtheriae. The thinner walls of Gramnegative bacteria probably account for considerably less than $20 \%$ of the total weight. The thickness of the staphylococcal cell wall has been estimated at 15 to $20 \mathrm{~m} \mu$, while that of Gram-negative bacilli, like Bact. coli and salmonellae, is around 10 to $15 \mathrm{~m} \mu$ and of Mycobacterium tuberculosis $23 \mathrm{~m} \mu$. The selective rigidity of the outer casing is demonstrated by the finding that the cell walls of rod-shaped organisms when specially prepared for electron microscopy retain their cylindrical form, whereas the protoplast assumes a spherical form when the cell wall is dissolved by lysozyme. Cell wall suspensions have a milky white opalescent appearance, and in the case of chromogenic bacteria there is no contained pigment which is associated with the small particles in the cytoplasm.

There is considerable variation in the chemical composition of the cell walls in different bacterial species, the main constituents being peptide-poly- 


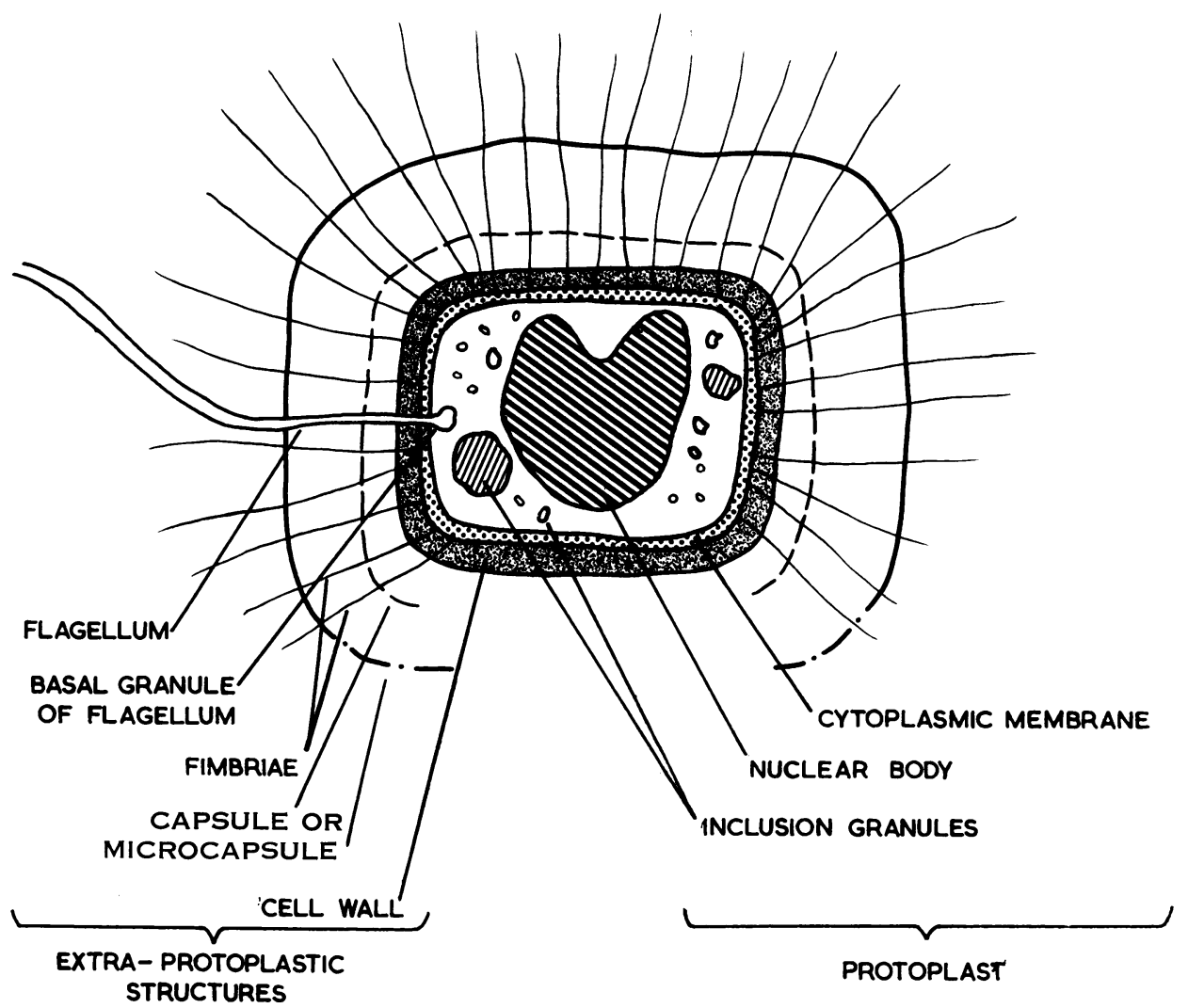

FIG. 1.-Diagrammatic representation of a bacterial cell (extracellular structures omitted at bottom of figure).

saccharide complexes. Certain major differences occur between the Gram-positive and Gramnegative organisms, the former having a limited range of amino-acids, whereas the Gram-negative bacteria have the same full range of amino-acids as have most proteins. The lipid content of the cell wall in Gram-negative bacteria is usually much greater than that of Gram-positive organisms (around $20 \%$ compared with $2-4 \%$ ), and this high content of lipid may be related to the lipo-polysaccharide of the $\mathrm{O}$ antigen or endotoxin. Polysaccharides and hexosamine are present in about equal amounts in both Gram-positive and Gramnegative bacteria.

In the past few years more detailed analyses have been made of the chemical content of the cell wall and its possible precursors (see Park, 1958). Thus, analysis of staphylococcal cell walls has shown that muramic acid, D-glutamic acid, lysine and DL-alanine are present in a ratio of about $1: 1: 1: 3$, while examination of penicillin-inhibited staphylococci revealed an accumulation of a uridine-5'-pyrophosphate complex which could be a cell wall precursor, since it contained muramic acid and the amino-acids in the same ratio (Park and Strominger, 1957). These findings may be linked to the early suggestion by Duguid (1946), following observed morphological changes in penicillininhibited bacteria, that penicillin interferes specifically with the formation of the cell wall while allowing growth to proceed until the organism bursts its defective envelope and so undergoes lysis, and to the recent observations by Cooper $(1954,1955)$ that penicillin is specifically bound to a bacterial lipid fraction which could be the cytoplasmic membrane. At last we seem to be learning something about the mode and site of action of penicillin and perhaps of other antibiotics.

Another application of our knowledge of the chemistry of the cell wall concerns the action of lysozyme, which acts on a mucopolysaccharide with the release of $\mathrm{N}$-acetyl hexosamine. When resistant variants of the susceptible $M$. lysodeikticus are obtained, chemical analysis shows no change in their sugar or amino-acid content but a 100 -fold increase in the $\mathrm{O}$-acetyl group. These 
findings suggest that lysozyme resistance may be due to an ability of the organism to acetylate certain cell wall hydroxyl groups associated with the substrate, which in the sensitive strains are free and receptive (Brumfitt, Wardlaw, and Park, 1958).

Other lytic enzymes, such as that derived from Streptomyces albus, act on cell walls and can be used for preparing bacterial solutions for precipitation reaction, such as Lancefield grouping.

\section{Capsules}

Much controversy and confusion have arisen over the definition of bacterial capsules, and various alternative or additional names have been used, such as envelope, slimy layer, ectoplasm, and outer coat. We may define a capsule as a microscopically demonstrable slimy or gelatinous layer covering the cell wall and having a definite external surface. The term "envelope" is used by some bacteriologists if the external boundary is not sharp or the slime has a tendency to dissolution ; others have described a "capsule membrane," but there seems no sound support for either of these two terms. A good deal of the confusion has arisen from difficulties in the demonstration of the capsule. The two most reliable methods are the wet-film India ink technique, used as a negative stain, and the specific antigen-antibody reaction erroneously called the Neufeld Quellung or capsular swelling reaction. Duguid (1951), who gives a detailed description of the India ink method, found that of dry-film staining techniques the eosin serum method of Howie and Kirkpatrick (1934) was the best. Recently, Novelli (1953) and others have used Alcian blue as a capsule stain, since it is the only dye so far recorded which will stain the bacterial capsule without previous mordanting. With one or other of these reliable methods, there is unanimity about the capsules of organisms like the pneumococcus, the anthrax bacillus, or Friedländer's bacillus. With Pasteurella pestis, on the other hand, there has been much divided opinion about capsule and envelope. Amies (1951) believed that the "envelope," dissolving in saline at $60^{\circ} \mathrm{C}$., is no more than a particularly well developed capsule which can be shown to persist despite solvents. In addition to these demonstrable capsules, certain bacteria may carry surface antigens or "microcapsules" (Wilkinson, 1958) separable and antigenically distinct from the cell wall, for example, the $\mathrm{M}$ antigen of Streptococcus pyogenes, which can be dissolved off by trypsin, without affecting the cell wall or viability.

Tomcsik and his colleagues (see Tomcsik, 1956) have used the specific capsular reaction (a more correct term than capsular swelling reaction) to study the structural elements in the capsule and also as an indicator of the localization of surface antigens. When specific antiserum is added to capsulated bacteria, a precipitation reaction quickly occurs which renders the capsule visible without changing its size or shape. This reaction has been used in the identification of such bacterial species as pneumococcus, streptococcus, Klebsiella, Haemophilus, Neisseria, Pasteurella, and Bacillus, and has helped to show that the capsular substance of the anthrax bacillus is not a polysaccharide but a glutamic acid polypeptide, while that of Pasteurella pestis is also a protein or a proteinpolysaccharide complex.

\section{Flagella}

Flagella are unusual in that they lie outside the cell wall and may be removed without killing the cell, yet have a characteristic movement which indicates that they are part of the living cell. Despite the ingenious artistry and arguments of Pijper, we may accept the flagella as locomotor organelles with their origin in a basal granule inside the cell wall. Structurally, they are non-tapering filaments in the shape of a cylindrical helix, which may have either one of two different wavelengths. The filaments vary in length up to $12 \mu$ and are approximately $12 \mathrm{~m} \mu$ thick. Chemically they are composed predominantly of protein made up of elongated molecules (molecular weight 41,000 ) with a characteristic amino-acid composition from which histamine, tryptophane, proline, and cysteine are lacking. The great variety of antigenic entities among flagella with very similar protein content suggests that these antigenic differences depend on the arrangement rather than the composition of the amino-acids ; this plasticity may also account for the variation from specific to group phase which characterizes many salmonella flagella.

In stained preparations of flagellated bacteria the actual number of flagella is much greater than are seen in vivo under dark-ground or phasecontrast microscopy. This difference is probably due to a tendency for flagella to aggregate with any motion ; aggregation into quite thick filaments is particularly well seen in the elongated forms of $B$. proteus grown on agar in the presence of penicillin (see Fleming, Voureka, Kramer, and Hughes, 1950). When flagella have been broken off from a young culture they regenerate within half an hour ; on the other hand, there is no evidence that they wear themselves out or even become frayed by active movement. 
Space does not allow any discussion of the interesting studies of Stocker and others on the genetic transductions of flagella and motility.

\section{Fimbriae}

Before we pass inside the cell wall mention must be made of another type of appendage, the short, slender and very numerous fibres, called fimbriae by Duguid, Smith, Dempster, and Edmunds (1955) and Duguid and Gillies (1957) to denote a fringe which surrounds many species of Gram-negative bacteria (Bact. coli, Bact. cloacae, Salmonella, Shigella flexneri, but not Sh. sonnei or shigae. They are about half the thickness of flagella, and fimbriation is enhanced by frequent passage in broth culture but has no relationship to motility. These fimbriae have strong adhesive properties and are responsible for agglutination of the red cells of various animal species. The fimbriae from different serological types of Shigella flexneri are antigenically similar and may be responsible for some of the non-specific agglutinins present in the blood in many individuals. It is still uncertain what function, if any, they serve.

\section{The Protoplast}

Separation of the cytoplasm from the cell wall was observed many years ago by Fischer (1900), who described as "plasmoptysis" the ejection of the cytoplasm from organisms like $B$. anthracis and Vibrio proteus. The empty casing either adhered to or was separated from the cytoplasm, which then assumed a spherical form. This phenomenon was recently rediscovered by Stähelin $(1953,1954)$ in weak-walled anthrax bacilli. The term protoplast was, however, first used by Weibull, who dissolved the cell wall of $B$. megaterium by lysozyme and maintained the spherical naked cell in a stabilizing solution of sucrose or polyethylene glycol for at least 24 hours. Attached flagella can be demonstrated in the intact cell although motility does not occur, probably for physical reasons. The protoplasts disintegrate rapidly in non-stabilizing solutions or if the suspension is aerated and the lysate is seen to contain " ghosts" or empty vesicles and small granules. The ghosts, which probably represent the cytoplasmic lining, are composed of delicate membranes and contain most of the pigmented material of the cell. The metabolism of protoplasts and whole bacterial cells is remarkably similar, so that, besides the cytochrome system, most of the cell's enzymic activity is contained within the protoplast. Phage production and spore formation also occur, provided these phenomena have been initiated before dissolution of the cell wall. To quote McQuillen
(1956), who has carried out many interesting studies with protoplasts :

"Intact bacteria and the protoplasts derived from them have closely parallel capabilities. Both forms respire; both synthesize proteins and nucleic acids and form adaptive enzymes; both can support the multiplication of virulent and temperate bacteriophages ; both can support the development of endospores; both grow in appropriate media ; and both can divide. Moreover, many of these activities are carried out at approximately similar rates and to similar extents by the two forms, the whole and the part. And yet the part is not the whole; there are differences in behaviour. To what extent some of these differences are due to the use of unsuitable conditions is not yet known."

Protoplasts cannot build a cell wall, possibly because a starter of cell wall material is needed before more can be laid down. Similarly, the failure to sporulate unless the process has already been initiated probably means that cell wall is needed to complete spore formation. Again, although phage will multiply inside the protoplast, this body cannot be infected with virulent phage, which seems to need the cell wall for initial penetration.

\section{The Nuclear Material}

Fierce arguments have been raging for some years on the nature and interpretation of the changes that are demonstrable in the chromatin bodies or nuclear material of the bacterial cell during the process of growth and division. The argument largely turns on whether the chromatin bodies which grow in number with the growth of the cell are composed of chromosomes which divide like the chromosomes of animal and plant cells, i.e., by mitosis, or whether they divide directly or amitotically, as happens with many of the higher bacteria and Protista. The opposing views are set out by Robinow and DeLamater respectively in their chapters in the Symposium on Bacterial Anatomy (1956). Robinow, using Feulgen and acid Giemsa stains, has studied particularly the development of the single chromatin body in germinating spores, and his interpretations of the observed phenomena carry convincing evidence for direct amitotic division. DeLamater has used the actively growing cell for his studies, and, having perhaps too readily assumed that bacteria divide by mitosis, interprets his findings to fit this hypothesis. He claims that both $B$. megaterium and Bact. coli have three chromosomes which can be shown pictorially to divide simultaneously by a complex mitotic mechanism inside the nuclear membrane. He and his colleagues also describe mitochondria and a centriole, which Robinow, on the other hand, regards as an acces- 
sory chromatin granule. It is impossible for the layman to adjudicate on the merits of these divergent stories by highly specialized cytologists, but support can be given to DeLamater's viewpoint that the truth will best be elicited by the simultaneous application of other techniques, such as those of biochemistry and bacterial physiology along with the cytochemical methods of the cytologist.

If we turn for a moment to the evidence of the microbial geneticist, it is obvious that genetic exchange of nuclear material takes place as a result of sexual pairing in certain species; in addition, transfer of genes occurs to cause the phenomena of transformation in pneumococcus and haemophilus types and of transduction of toxigenicity in $C$. diphtheriae or motility in salmonella. The cytologists have so far been unable to contribute to a better understanding of these strange happenings, although there has been some correlation between cytological changes and genetic exchange in higher organisms like Drosophila and maize. There is little doubt that D.N.A. is the active principle in the genetic mutations of bacteria, mediated sometimes through bacteriophage. It has also been shown that genetic differentiation of the D.N.A. material is linear, i.e., the "bacterial chromosome" may be regarded as a long, thread-like D.N.A. molecule, carrying the genes in an orderly sequence like the inscription on a tape. The D.N.A. molecule, pictured by Watson and Crick (1953) as a cylindrical double helix with a diameter of $2.5 \mathrm{~m} \mu$, would correspond to a thread about 1,000 times the length of the parent bacterial cell. Attempts at cytological study of the D.N.A. molecule are now being made by electron microscopic examination of ultra-thin sections of bacteria. It is suggested that the thread is coiled up to form a tube, and in the photomicrographs of Maaløe and Birch-Andersen (1956) tube-like structures cut in all different directions can be demonstrated. It may be possible in the future to learn more about the nucleus and its mode of division by detailed studies of this kind.

\section{Cytoplasm and Inclusion Bodies}

In electron photomicrographs of sectioned bacteria (staphylococci, streptococci, paracolon bacilli, aerobacter, mycobacteria) the cytoplasm seems to consist of fine granules of 10 to $20 \mathrm{~m} \mu$ with sometimes larger granules, the total number in a single cell being of the order of $10^{4}$ to $10^{5}$. Chemically the cytoplasm is composed mainly of ribonucleic acid and protein and contains most of the enzymic activity of the cell, partly in its membrane. The small size of the granule and the multiplicity of enzymes in many bacteria suggest that there will be numerous enzymically different types of granules. They are probably derived from the nucleus, growing by the formation or accumulation of enzyme proteins. In discussing the relationship of bacterial cytoplasm to that of other lowly creatures, Bradfield states that :

\begin{abstract}
" the most striking structural difference between bacterial cytoplasm and the cytoplasm of animals and plants is the absence from bacteria of all kinds of intra-cytoplasmic membranes; the oxidative granules are not wrapped in membranes to form mitochondria; the RNA-rich granules are not arrayed on membranes to form endoplasmic reticulum ; and finally the cytoplasm as a whole is not separated from the nucleus by a nuclear membrane."
\end{abstract}

Among inclusion bodies, the most commonly seen are the Babes-Ernst metachromatic bodies, often called volutin granules. These metachromatic granules, seen best in $C$. diphtheriae and ranging in size up to $0.6 \mu$, are very electron opaque and chemically contain polymetaphosphate and probably other phosphorus compounds. Smith, Wilkinson, and Duguid (1954) found that, although volutin granules might account for $20 \%$ of the bacterial volume, only $1 \%$ of the dry weight was polymetaphosphate.

Wilkinson and his colleagues (Williamson and Wilkinson, 1958 ; Macrae and Wilkinson, 1958) have also studied the lipid inclusions found particularly in the larger varieties of the Bacillus species. These lipid granules, which are composed mainly of a polymer of $\beta$ hydroxybutyric acid, are most numerous in cells about to sporulate or when grown in semi-synthetic culture media containing an excess of glucose, pyruvate, or $\beta$ hydroxybutyrate as the main carbon sources for metabolism. They are regarded by the Edinburgh workers as stores of carbon and energy and are probably used up in the process of sporulation. Whether inclusion bodies like volutin and the lipid globules serve a specific function in cellular metabolism, or whether they represent an abnormal or pathological state of the bacterial cell, is a debatable point. As already mentioned, the pigments of chromogenic bacteria are found predominantly within the cytoplasm, and Schachman, Pardee, and Stanier (1952) have observed many well-defined chromatophores of approximately $40 \mathrm{~m} \mu$ diameter in the cytoplasm of Rhodospirillum rubrum. They were absent from organisms grown in the dark. Probably many other photosynthetic bacteria possess similar chromatophores. 


\section{Osmotic Activity of the Bacterial Cell}

Having discussed some aspects of bacterial anatomy, we may conclude with a reference to the bacterial cell's mode of living. As with other cells, the active life and growth of bacteria depend on an interchange of nutrient and waste products between the interior of the cell and the external environment. This involves a selective intake of nutrient molecules and the expulsion of waste molecules, while the vital enzymic and nuclear substances of the cytoplasm are retained. There is good evidence that the cytoplasmic lining membrane functions as a selective osmotic barrier, while the outer wall maintains the structural rigidity of the cell. The bacterial cell is remarkably resistant to violent changes in its environment and will remain intact in media ranging from distilled water to strong salt solutions, although this tolerance is considerably reduced in the young, actively growing phase. Bacteria react by swelling or shrinking in media of high or low osmotic pressures, but the reaction is selective in that, as Fischer showed more than 50 years ago, plasmolysis of Gram-negative bacteria occurs in high concentrations of salt or sucrose but not in similar concentrations of glycerol or urea. During plasmolysis the cell wall does not shrink with the protoplast, the contents of which stream out in a series of fine droplets. Gram-positive bacteria are much more resistant to plasmolysis, but they, too, respond by contraction selectively to hypertonic solutes of sucrose but not of glycerol. This indicates that they resemble Gram-negative bacteria except that the plasma membrane does not easily separate from the cell wall, although there is good evidence that it is a distinct structure. The osmotic pressure inside the cell may be as high as 20 atmospheres, and the tensile strength of the cell wall, greater in spherical than in cylindrical organisms, is responsible for withstanding the high pressures. Obviously if this tensile strength is weakened, as by the action of penicillin, the phenomenon of plasmolysis or plasmoptosis will readily occur.

The functionally active plasma membrane is composed of lipid and protein and is estimated to be $15 \mathrm{~m} \mu$ thick if hydrated, or $5 \mathrm{~m} \mu$ if unhydrated. This corresponds to the classical semipermeable membrane 2-4 molecules thick. The cell wall must also be permeable, and Mitchell and Moyle (1956) suggested that it consists of a network of chains or fibres, with an effective pore diameter of about $1 \mathrm{~m} \mu$. Indeed, although the plasma membrane is the important osmotic barrier to small molecules, the cell wall probably acts as the barrier to solutes of 10,000 molecular weight or over. However, the cytoplasmic membrane is, according to the experiments by Mitchell and Moyle and others, more than a semi-permeable barrier, for it contains the bulk of the cytochrome system and other enzymes, and it may act as a carrier of substances into and out of the cell, a process called exchange diffusion. This may explain the selectivity of the osmotic barrier, which would on this hypothesis be dependent on the presence of carrier enzymes which act as ferry boats for the transport of selected passengers into and out of the cell.

\section{REFERENCES}

Amies, C. R. (1951). Brit. J. exp. Path., 32, 259

Brumfitt, W., Wardlaw, A. C., and Park, J. T. (1958). Nature (Lond.),

181, 1783.
Cohn, F. (1875). Beitr. Biol. Pfl., 1, Heft 2, p. 127.

Cohn, F. (1875). Beitr. Biol. Pfl, 1, Heft 2, p. 127.
Cooper, P. D.(1954). J. gen. Microbiol., 10, 236.

(1955). Ibid., 12, 100.

DeLamater, E. D. (1956). Bacterial Anatomy (6th Symposium of the Society for General Microbiology), p. 215. University Press, Cambridge.

Duguid, J. P. (1946). Edinb. med. J., 53, 401.

(1951). J. Path. Bact., 63, 673.

- and Gillies, R. R. (1957). Ibid., 74, 397.

Smith, I. W., Dempster, G., and Edmunds, P. N. (1955). Ibid., 70, 335 .

Fischer, A. (1900). Z. Hyg. Infect.-Kr., 35, 1.

Fleming, A., Voureka, A., Kramer, I. R. H., and Hughes, W. H. (1950).'J. gen. Microbiol., 4, 257.

Howie, J. W., and Kirkpatrick, J. (1934). J. Path. Bact., 39, 165.

Maaløe, O., and Birch-Andersen, A. (1956). Bacterial Anatomy (6th Symposium of the Society for General Microbiology), p. 261. University Press, Cambridge.

McQuillen, K. (1956). Ibid., p. 127.

Macrae, R. M., and Wilkinson, J. F. (1958). J. gen. Microbiol., 19, 210.

Mitchell, P., and Moyle, J. (1956). Bacterial Anatomy (6th Symposium of the Society for General Microbiology), p. 150. University Press, Cambridge.

Novelli, A. (1953). Experientia (Basel), 9, 34.

Park, J. T. (1958). The Strategy of Chemotherapy (8th Symposium of the Society for General Microbiology), p. 49. University Press, Cambridge.

. and Strominger, J. L. (1957). Science, 125, 99.

Robinow, C. F. (1956). Bacterial Anatomy (6th Symposium of the Society for General Microbiology), p. 181. University Press, Cambridge.

Schachman, H. K., Pardee, A. B., and Stanier, R. Y. (1952). Arch. Biochem., 38, 245 .

Smith, I. W., Wilkinson, J. F., and Duguid, J. P. (1954). J. Bact., 68,450 .

Stähelin, H. (1953). Schweiz. Z. allg. Path., 16, 892.

(1954). Ibid., 17, 296.

Tomcsik, J. (1956). Bacterial Anatomy (6th Symposium of the Society for General Microbiology), p. 41. University Press, Cambridge.

Watson, J. D., and Crick, F. H. C. (1953). Nature (Lond.), 171, 737

Wilkinson, J. F. (1958). Bact. Rev., 22, 46.

Williamson, D. H., and Wilkinson, J. F. (1958). J. gen. Microbiol. $19,198$. 